\title{
DOI 10.31489/2020No1/26-34
}

\section{UDC 538.9}

\section{PHASE TRANSFORMATIONS IN FERRITES DURING RADIATION-THERMAL SINTERING}

\author{
Surzhikov A.P. ${ }^{1}$, Lysenko E.N. ${ }^{1}$, Malyshev A.V. ${ }^{1}$, Petrova A. ${ }^{1}$, \\ Ghyngazov S.A. ${ }^{1}$, Aimukhanov A.K. ${ }^{2}$ \\ 1National Research Tomsk Polytechnic University, Tomsk, Russia, malyshev@tpu.ru \\ 2E.A. Buketov Karaganda State University, Karaganda, Kazakhstan
}

\begin{abstract}
Electron microscopic studies of the phase composition, morphology, and defect structure of lithium-titanium ferrite powders and ceramic samples sintered under conditions of radiation-thermal and thermal effects were carried out. Radiation-thermal sintering of ferrite samples was carried out by irradiating the work pieces with a pulsed electron beam with energy of (1.5-2.0) MeV using the electron beam accelerator. The beam current in the pulse was (0.5-0.9) A, the irradiation pulse duration was $500 \mu \mathrm{s}$, the pulse repetition rate was (5-50) $\mathrm{Hz}$, and the work piece heating rate was $1000{ }^{\circ} \mathrm{C} / \mathrm{min}$. The samples were irradiated in a box of lightweight fireclay with a bottom thickness of $15 \mathrm{~mm}$. The microstructure studies were conducted by the methods of electron diffraction microscopy in the light using an electron microscope. It was shown that the most probable model of radiation intensification of the sintering process of ferrites can be the mechanism of radiation retardation of dislocations upon heating, which are formed during the decomposition of subgrain boundaries in grains of intermediate phases of ferrite.
\end{abstract}

Keywords: lithium-titanium ferrite, powder, sintering, electron beams, electron microscopy, morphology, phase composition, defectiveness.

\section{Introduction}

The most universal requirement for the microstructure of ferrites is the condition for the maximum density of the material and the equigranularity of its structure $[1,2]$. For complying with these requirements, at economically reasonable firing times, several methods to increase the activity of sintering processes were developed. This is the two-stage introduction of the components, the pre-blending of ferrite with a ferrite powder of the same composition, the presence of a liquid phase, forced sintering, and the application of ultrasound to the sintering process [1,3-9]. In recent years, the usage of the effects of ionizing radiation fluxes in the preparation and modification of materials was developed. Of the variety of ionizing radiation in radiation materials science, the most widely used are the flows of accelerated electrons. This is due, firstly, to the progress of accelerator technology, the creation of relatively small but powerful electron accelerators.

Secondly, electron beams have convenient geometric characteristics, wide opportunities to control the irradiation regime, do not create induced radioactivity, have a lower cost in comparison with other sources of ionizing radiation, and have a high efficiency of converting electricity to electron beam energy.

The first works on the implementation of solid-phase transformations in inorganic materials using high-temperature electron irradiation were studies on the synthesis of cement clinker [10,11], hexagonal barium ferrite [12] and lithium ferrite [13], as well as sintering under such specific conditions of europium oxide [14], alumina-containing blends [15] and ferrite compacts [16-18]. Sintering was most fully studied under the conditions of combined exposure to high temperatures and intense electron flows [19]. The regularities of ferrite compacts compaction were established 
[20]. In particular, multiple increases in the compaction rate of lithium-titanium ferrite compacts under such sintering conditions were shown $[13,21]$. Microscopic methods have been used to study in detail the formation of a microstructure under conditions of such kind of processing [22].

In this case, the question remains open about the features of the formation of the magnetic characteristics of ferrites. Data on phase transformations in ferrites during radiation-thermal (RT) sintering are important and productive. For that purpose in this work was used electron microscopy to study the features of phase transformations of ferrite ceramics sintered under RT conditions. The inapplicability of the $\mathrm{X}$-ray phase analysis method for lithium ferrites is due to the overlapping of the main phase lines $\mathrm{LiFe}_{5} \mathrm{O}_{8}, \mathrm{LiFeO}_{2}, \mathrm{Fe}_{3} \mathrm{O}_{4}$.

\section{The object of the study and experimental technique}

In this work powders of lithium-titanium ferrite synthesized from a mechanical mixture of oxides and carbonates containing: $\mathrm{Li}_{2} \mathrm{CO}_{3}-11.2$ wt.\%; $\mathrm{TiO}_{2}-18.65$ wt.\%; $\mathrm{ZnO}-7.6$ wt.\%; $\mathrm{MnCO}_{3}-2.74$ wt.\%; remain $-\mathrm{Fe}_{2} \mathrm{O}_{3}$ were used. After weighing the components according to the recipe, they are jointly ground and mixed in a vibratory mill for $1 \mathrm{~h}$, after adding to the mixture of distilled water in the ratio (by weight) the mixture: water, equal to 1: 2. After the vibratory mill, the mixture is dried at $80{ }^{\circ} \mathrm{C}$ under normal atmospheric pressure for 24 hours and then wiped through a 0.7 sieve. Distilled water is introduced into the obtained powder in an amount of $10 \%$ by weight of the powder and briquetted. Briquettes are heated in thermal furnaces at a speed of $200{ }^{\circ} \mathrm{C} / \mathrm{h}$ to $900{ }^{\circ} \mathrm{C}$, maintained at this temperature for 6 hours, cooled to room temperature, after which they are crushed, ground and sieved through a 0.9 sieve.

After repeated grinding in a vibration mill for 45 minutes, $\mathrm{Bi}_{2} \mathrm{O}_{3}$ dissolved in concentrated nitric acid in suspension ( $0.22 \mathrm{wt} . \%)$ Is added to the powder and mixing is carried out in a ball mill for 4 hours. Determination of the quality of the powder is carried out according to the method developed by our scientific group. For preparing a press powder, a $10 \%$ solution of polyvinyl alcohol in an amount of $12 \mathrm{wt} . \%$ of the charge, and the resulting mass is alternately wiped through a sieve of 0.7 and 0.45 . Press-samples for studying sintering processes are made by cold unilateral pressing in the form of tablets (diameter $15 \mathrm{~mm}$ and thickness $2 \mathrm{~mm}$ ). The pressing pressure is selected, as a rule, experimentally for each specific ferrite composition according to the established dependence of the bulk density $\rho$ of the samples on the pressing pressure $\mathrm{P}$.

Pressing pressure varied within (25-500) MPa. Sintering of the press-samples was carried out in a thermal furnace at $1100{ }^{\circ} \mathrm{C}$ for $30 \mathrm{~min}$ in an air atmosphere at a heating rate of $900{ }^{\circ} \mathrm{C} / \mathrm{min}$. Such a high speed is achieved by introducing press samples into a furnace heated to a predetermined temperature.

It has been established that at pressing pressures below $40 \mathrm{MPa}$, the press samples are characterized by low density, and at pressing pressures of more than $250 \mathrm{MPa}$, the samples have cracks and delaminations (the phenomenon of repressing). Thus, the most optimal pressing pressure, which provides an acceptable density of both raw and sintered samples, is in the range (110-200) $\mathrm{MPa}$. The following pressing mode was used in the work: $\mathrm{P}=130 \mathrm{MPa}$, the exposure time of the material under pressure $1 \mathrm{~min}$; and two modes of sintering of press samples: radiationthermal (RT) and thermal (T).

RT-sintering was carried out by irradiating the workpieces with a pulsed electron beam with energy of (1.5-2.0) MeV using the ILU-6 accelerator. The beam current in the pulse was (0.5-0.9) A, the irradiation pulse duration was $500 \mu \mathrm{s}$, the pulse repetition rate was (5-50) $\mathrm{Hz}$, and the workpiece heating rate was $1000{ }^{\circ} \mathrm{C} / \mathrm{min}$. The samples were irradiated in a box of lightweight fireclay with a bottom thickness of $15 \mathrm{~mm}$. On the irradiation side, the box was covered with a radiation-transparent tread of mass thickness $0.1 \mathrm{~g} \mathrm{~cm}^{-1}$. The temperature was measured by a control sample placed close to the sintered blanks. Sintering in thermal furnaces (T-sintering) was carried out in a preheated chamber electric furnace, which provided a heating rate comparable to the rate of 
radiation heating. The cell design and temperature control technique are similar to those used in RTsintering. Both sintering modes were carried out in the air.

The studies were conducted by the methods of electron diffraction microscopy in the light using an electron microscope of the EM-125K brand at an accelerating voltage of $125 \mathrm{kV}$. The phase composition of the analyzed materials was determined by indicating microelectron diffraction patterns of objects. Due to the fact that the diameter of the microdiffraction analysis zone did not exceed $0.7 \mu \mathrm{m}$, the method is local and allows the phase analysis of individual grains and subgrains.

The morphology and defective structure of the material were studied by the bright field method obtained by direct passage of an electron beam through a thin sample, as well as by the dark field method, when the image of the material structure is formed in one of the diffracted electron beams.

\section{Results and discussions}

Indication of electron diffraction patterns (taking into account the chemical composition of the samples) showed that the studied material is a complex multiphase product. The phases based on $\mathrm{LiFeO}_{2}$ (cubic lattice, $\mathrm{a}=4.1588 \AA$ ), $\mathrm{LiFe}_{5} \mathrm{O}_{8}$ (cubic lattice, $\mathrm{a}=8.337 \AA$ ), and $\mathrm{FeTiO}_{3}$ (hexagonal lattice, $\mathrm{a}=5.075 \AA, \mathrm{c}=14.06 \AA$ ) are confidently identified. The relative phase content was determined by indicating microelectron diffraction patterns and counting the number of contacts of the planes of the above phases in microelectron diffraction patterns. Phase analysis showed that the phase ratio is determined by the heat treatment of the material (Table 1).

Thus, in the initial powder, the total content of the $\mathrm{LiFeO}_{2}$ and $\mathrm{FeTiO}_{3}$ phases is 1.41 times higher than the $\mathrm{LiFe}_{5} \mathrm{O}_{8}$ phases. After heat treatment of the compacted powder in an electron beam (RT-sintering regime), on the contrary, the content of the $\mathrm{LiFe}_{5} \mathrm{O}_{8}$ phase is 1.5 times higher than the content of the $\mathrm{LiFeO}_{2}$ and $\mathrm{FeTiO}_{3}$ phases. Thermal sintering in the furnace also increases the relative content of the $\mathrm{LiFe}_{5} \mathrm{O}_{8}$ phase, but despite the twice as long heating time, this increase is not so significant compared to the RT sintering regime.

Table 1. Relative content of the main phases in Li-Ti ferrite

\begin{tabular}{|l|c|c|c|c|}
\hline \multicolumn{1}{|c|}{ Phase } & $\begin{array}{c}\text { Initial } \\
\text { powder }\end{array}$ & $\begin{array}{c}\text { Powder after heating } \\
\text { at } 1373 \mathrm{~K}, 2 \mathrm{~h}\end{array}$ & $\begin{array}{c}\text { Ceramic sample } \\
\text { sintered in T-regime at } \\
1373 \mathrm{~K}, 2 \mathrm{~h}\end{array}$ & $\begin{array}{c}\text { Ceramic sample sintered } \\
\text { in RT-regime at 1373 K, } \\
1 \mathrm{~h}\end{array}$ \\
\hline $\mathrm{LiFe}_{5} \mathrm{O}_{8}$ & 0.42 & 0.46 & 0.50 & 0.60 \\
\hline $\mathrm{LiFeO}_{2}$ & 0.29 & 0.16 & 0.05 & 0.04 \\
\hline $\mathrm{FeTiO}_{3}$ & 0.29 & 0.38 & 0.45 & 0.36 \\
\hline $\mathrm{LiFeO}_{2}+\mathrm{FeTiO}_{3}$ & 1.41 & 1.18 & 1.0 & 0.67 \\
\hline $\mathrm{LiFe}_{5} \mathrm{O}_{8}$ & 1.0 & 0.43 & 0.1 & 0.1 \\
\hline $\mathrm{LiFeO}_{2}$ & & & 0.1 & \\
\hline $\mathrm{FeTiO}_{3}$ & & & & \\
\hline
\end{tabular}

Powder heating also leads to a change in the ratio of $\mathrm{LiFeO}_{2}$ and $\mathrm{FeTiO}_{3}$ phases towards a decrease in the relative fraction of $\mathrm{LiFeO}_{2}$. In the compacted state of the sample, this process proceeds more intensively and does not depend on the sintering method. Take into account the complex component composition of the mixture from which the powder was synthesized, it should be assumed that the identified phases are in fact solid solutions of $\mathrm{Zn}, \mathrm{Mn}$ and Ti. This is evidenced, in particular, by our measurements of the Curie temperature of ferrite, which turned out to be 530 $\mathrm{K}$, which corresponds to solid solutions of lithium ferrites [23]. Morphological analysis of the structure of ferrites was carried out on photographs with electron microscopic images of the structure. Two morphological varieties of grains were established: polycrystalline aggregates (Figure 1a, 1b) and single-crystal particles. 


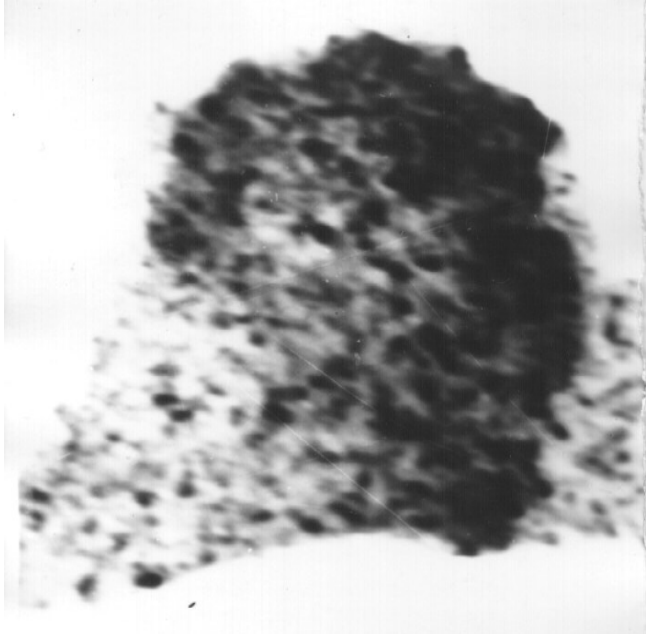

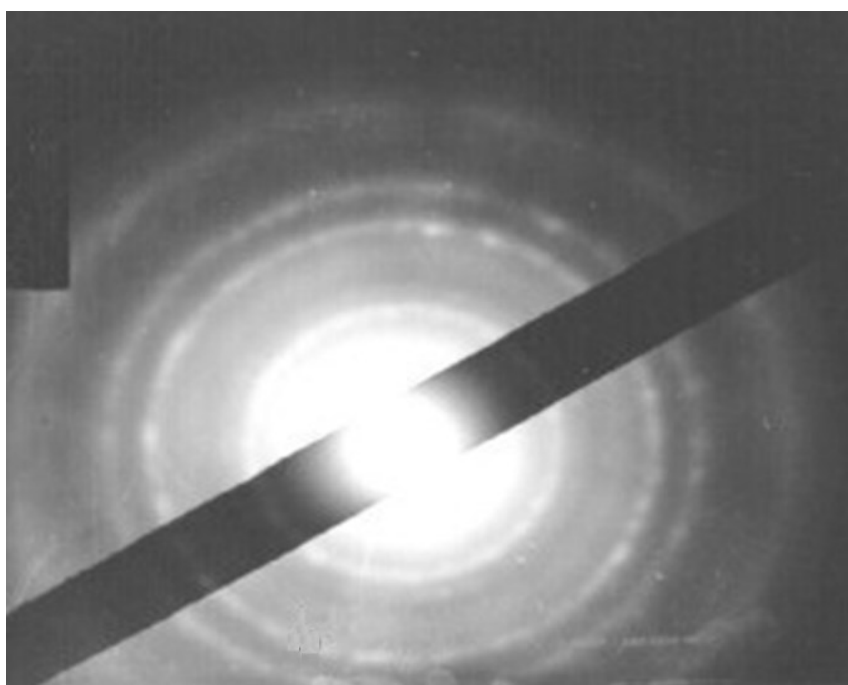

b

Fig.1. Polycrystalline aggregates of ferrite powder before sintering: $a-$ the structure image; $b$ - the structure electron diffraction pattern

Both aggregates and particles have a very diverse shape with average grain size $(0.5-0.8) \mu \mathrm{m}$. The sizes of the subgrains of polycrystalline aggregates are $(0.02-0.07) \mu \mathrm{m}$. Most single-crystal particles have an almost perfect structure, however, in some cases, polygonal dislocation networks were observed inside the particles. Local phase analysis of individual grains revealed that before heating, the $\mathrm{LiFeO}_{2}$ and $\mathrm{FeTiO}_{3}$ phases are represented as polycrystalline aggregates, while it was found that the $\mathrm{FeTiO}_{3}$ phase (Figure 2a) has a fine-grained structure compared to $\mathrm{LiFeO}_{2}($ Figure $2 b)$. So, in the first case, the average size of subgrains is $(0.02-0.04) \mu \mathrm{m}$, in the second - $(0.04$ 0.07) $\mu \mathrm{m}$. The $\mathrm{LiFe}_{5} \mathrm{O}_{8}$ phase is a single crystal particle. In some cases, under certain diffraction conditions, a domain structure can be observed inside such particles. Grains that are polyphase aggregates were rarely found (Figure 3). In this case, reflections from all the above phases are simultaneously present in the microdiffraction pattern.

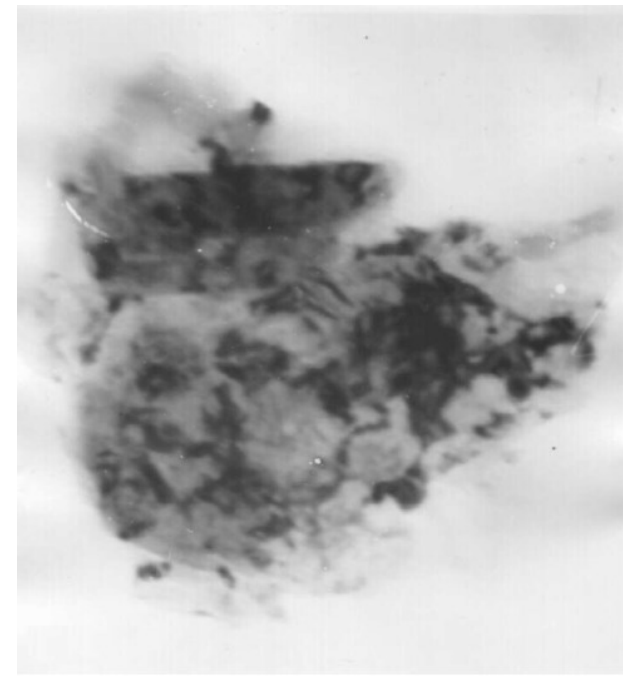

a

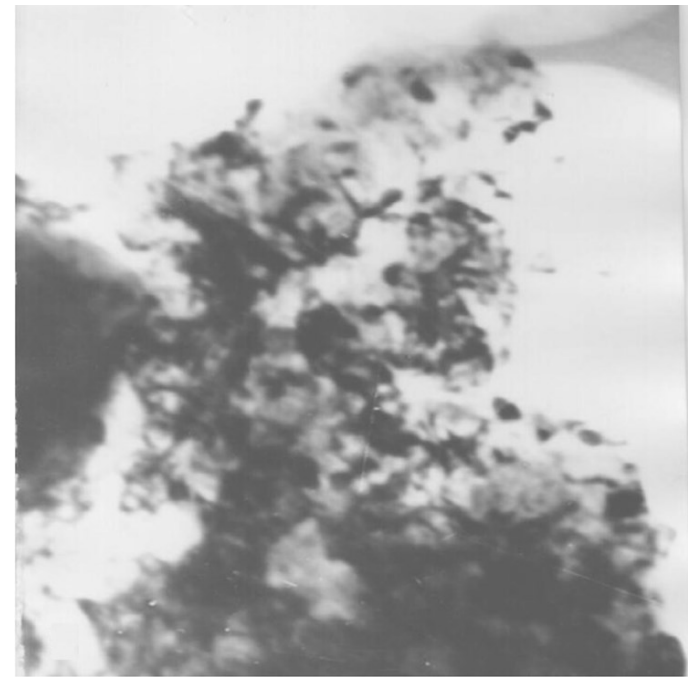

$\mathrm{b}$

Fig. 2. Electron microscopic images of ferrite powder before sintering: $\mathrm{a}$ - the phase $\mathrm{FeTiO}_{3} ; \mathrm{b}$ - the phase $\mathrm{LiFeO}_{2}$ 
In some cases, under certain diffraction conditions, a domain structure can be observed inside such particles. Rarely found grains, which are polyphase aggregates (Figure 3). In this case, reflections from all the above phases are simultaneously present in the microdiffraction pattern. The morphological state of the $\mathrm{LiFe}_{5} \mathrm{O}_{8}$ phase has high thermal stability: under all processing conditions, it is observed only in the form of single-crystal particles. The morphology of the $\mathrm{LiFeO}_{2}$ and $\mathrm{FeTiO}_{3}$ phases depends on the processing method. So, in the case of a loose powder, the subgrain structure coarsens to an average grain size of $0.09 \mu \mathrm{m}$. Thermal sintering of the pressed powder leads to an almost complete transition of polycrystalline aggregates (Figure 4) into singlecrystal particles (Figure 5) (the ratio of the two types of structures is 9:1).

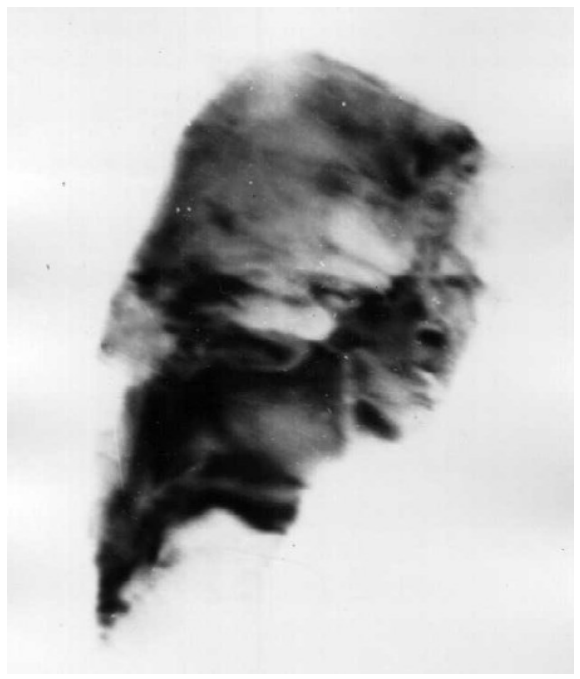

a

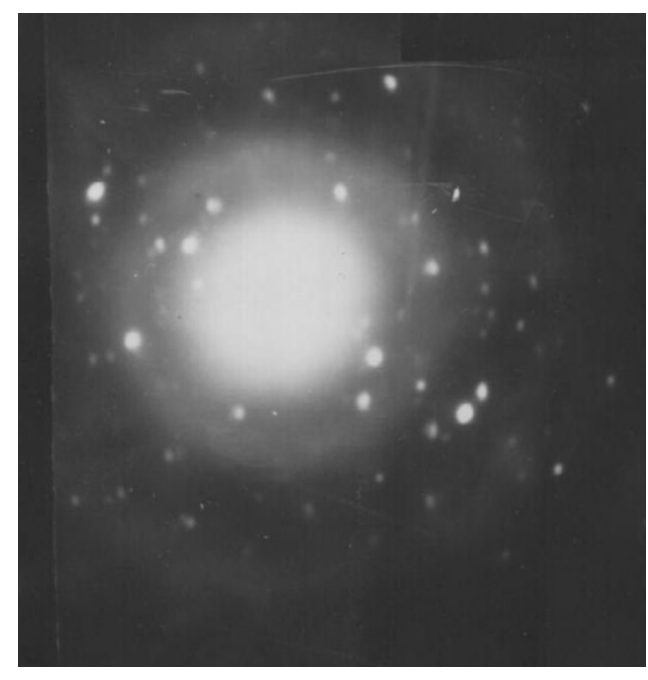

b

Fig.3. Polyphase aggregates of ferrite powder before sintering: $\mathrm{a}$ - the structure electron microscopic image; $\mathrm{b}$ - the structure electron diffraction pattern

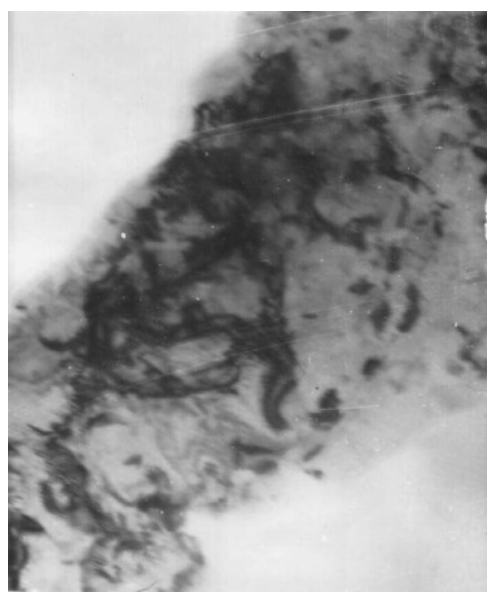

a

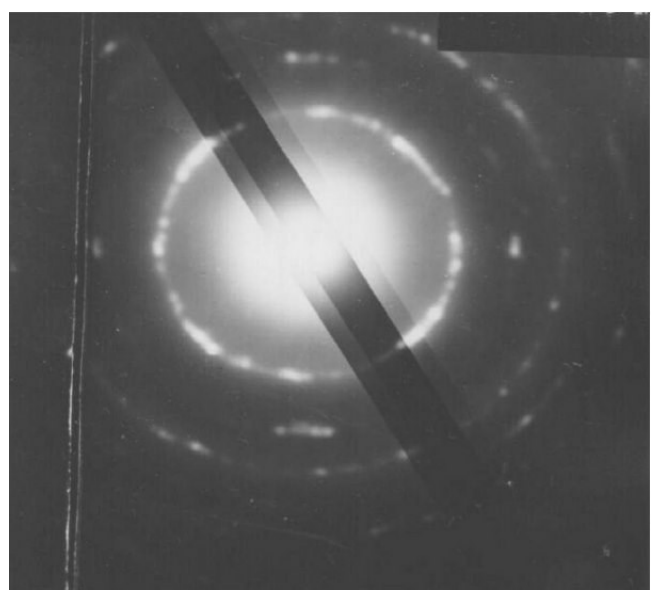

b

Fig.4. Polycrystalline compressed powder aggregates:

$\mathrm{a}$ - the structure electron microscopic image; $\mathrm{b}$ - the structure electron diffraction pattern

Sintering of the pressed powder by an electron beam eliminates polycrystalline aggregates with an ultrafine grain structure; only a coarse-grained structure is observed in ceramics. Grains formed in the process of destruction of the polycrystalline structure have a large block structure and a dislocation structure. In this case, in contrast to T-sintering, in grains after RT-sintering, a higher number of dislocations remain. A characteristic feature of ceramic materials (unlike powders) is the presence of a large number of polyphase grains (Figure 6). Moreover, judging by the intensity of 
reflections in microdiffraction patterns, after thermal sintering, the phases $\mathrm{LiFeO}_{2}$ and $\mathrm{FeTiO}_{3}$ have advantages in such grains. After RT sintering, the total content of these phases is compared with the amount of $\mathrm{LiFe}_{5} \mathrm{O}_{8}$ phase.

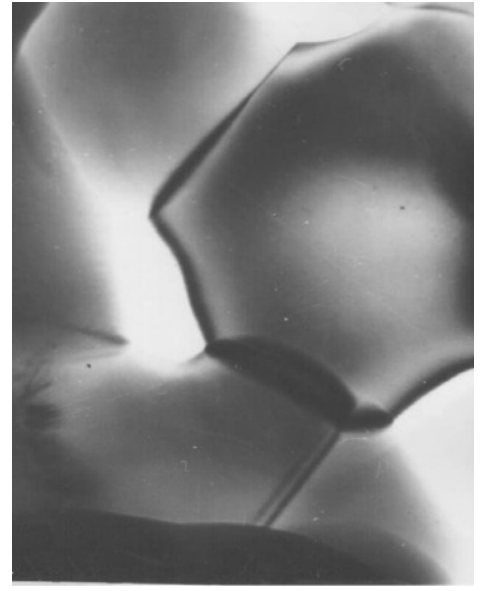

a

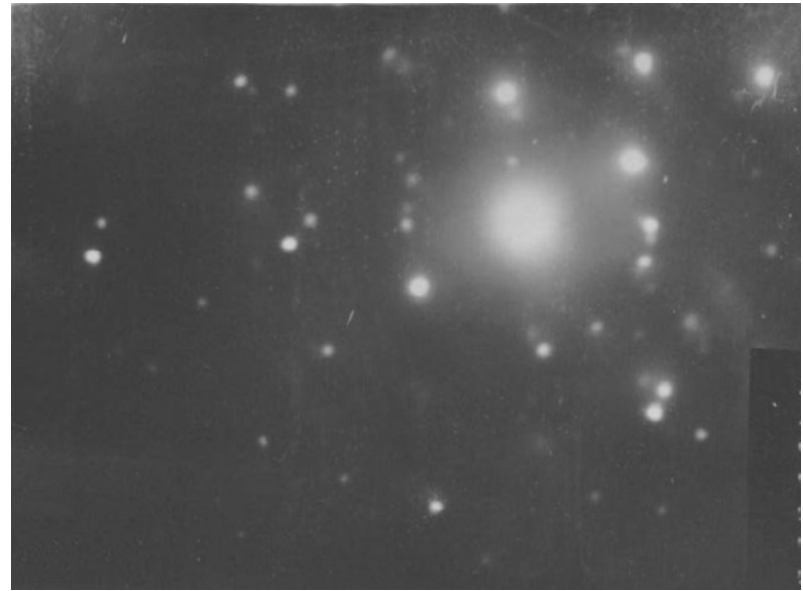

b

Fig.5. Single-crystal particles of ferrite ceramics after T-sintering for 3 hours at $1373 \mathrm{~K}$ : $\mathrm{a}$ - the structure electron microscopic image; $\mathrm{b}$ - the structure electron diffraction pattern

From the presented results, it follows that the initial powder used for sintering ceramic products is in a state of incomplete ferritization, since, along with the magnetic phase of $\mathrm{LiFe}_{5} \mathrm{O}_{8}$, the intermediate phases of synthesis, $\mathrm{LiFeO}_{2}$ and $\mathrm{FeTiO}_{3}$, are present in the powder. Such a structure of powders increases the sintering rate due to the high level of imperfection of the initial powder grains and is therefore widely used in ceramic technology [24-40].

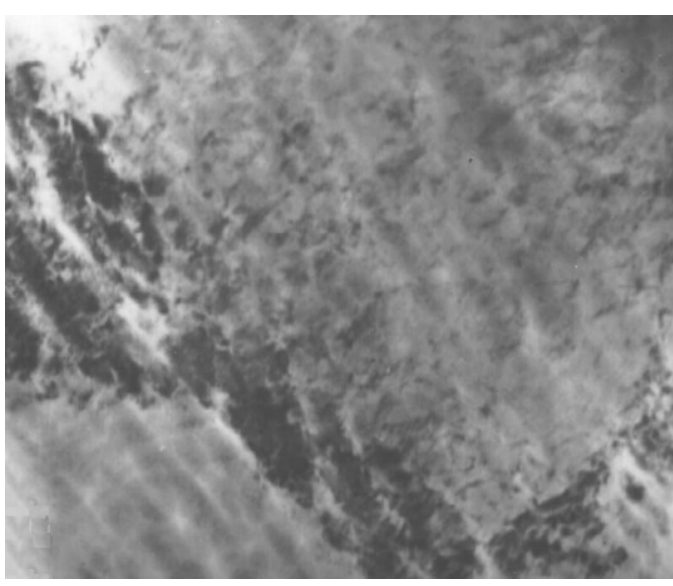

a

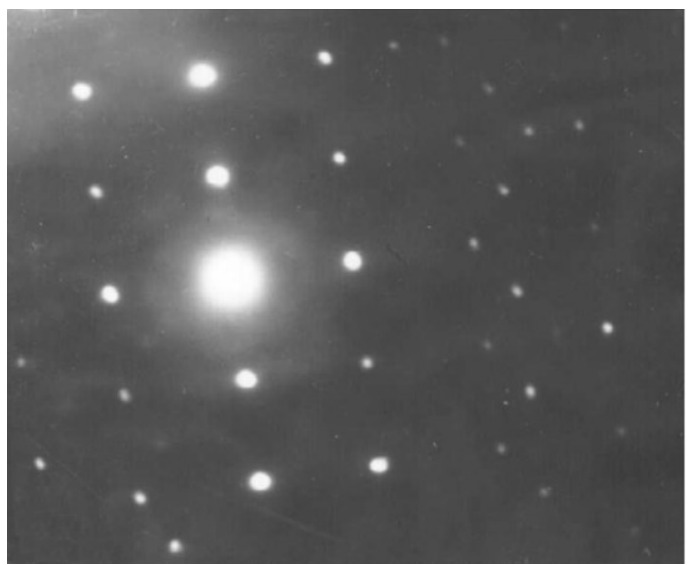

b

Fig.6. Polyphase grains of ferrite ceramics after RT-sintering for 3 hours at $1373 \mathrm{~K}$ : $\mathrm{a}$ - the structure electron microscopic image; $\mathrm{b}$ - the structure electron diffraction pattern

From this point of view, we are interested in the differences in the morphology of the main $\left(\mathrm{LiFe}_{5} \mathrm{O}_{8}\right)$ and intermediate $\left(\mathrm{LiFeO}_{2}, \mathrm{FeTiO}_{3}\right)$ phases: the excessive defectiveness of the $\mathrm{LiFeO}_{2}$ and $\mathrm{FeTiO}_{3}$ phases in the form of subgrain boundaries is apparently a significant factor in the increased activity of the initial powder. The chemical interaction between $\mathrm{LiFeO}_{2}$ and $\mathrm{FeTiO}_{3}$ with the formation of a solid solution based on $\mathrm{LiFe}_{5} \mathrm{O}_{8}$ occurs more intensively on compressed samples and using RT exposure (Table 1). The consequence of this effect is an increase in the number of grains with a mixed phase composition.

Considering the nature of the RT effect, it is necessary to pay attention to the increased activity of the decay of subgrain boundaries in the intermediate phases under the conditions of electron 
irradiation. The consequence of this decay is the enrichment of the grain volume by dislocations, which, as is known, accelerates the diffusion processes of mass transfer. Higher content of dislocations in the irradiated material may be due to their radiation deceleration upon heating due to violation of the potential relief of the slip planes by point radiation defects. The same conclusion about the mechanism of RT activation of sintering of Li-Ti ferrites was made when analyzing the kinetic dependences of compaction of billets under similar irradiation conditions.

\section{Conclusion}

Based on the results of electron microscopy studies of the phase composition, morphology, and defective structure of $\mathrm{Li}-\mathrm{Ti}$ ferrites, the following conclusions can be drawn:

- the studied material in the initial and sintered states is a multiphase mixture consisting of solid solutions based on compounds $\mathrm{LiFeO}_{2}, \mathrm{FeTiO}_{3}$ и $\mathrm{LiFe}_{5} \mathrm{O}_{8}$;

- relative phase content is determined by the processing mode of the material;

- two morphological varieties of grains - polycrystalline aggregates with an ultrafine structure and single-crystal particles were revealed. By local diffraction analysis, it was found that the phases $\mathrm{LiFeO}_{2}$ and $\mathrm{FeTiO}_{3}$ have a polycrystalline structure; the $\mathrm{LiFe}_{5} \mathrm{O}_{8}$ phase is presented in the form of single-crystal particles;

- the thermal effect on the powder or the billet leads to the destruction of polycrystalline aggregates with the formation of large-block grains, inside which a dislocation structure is observed;

- sintering of the press blanks with an electron beam enhances the destruction of the nanograin structure, helps to preserve the dislocation substructure in the grains, and intensifies the processes of powder deferritization;

A probable model of the $\mathrm{RT}$ effect in $\mathrm{Li}-\mathrm{Ti}$ ferrites can be the mechanism of radiation retardation of dislocations upon heating, which are formed during the decay of subgrain boundaries in grains of intermediate ferrite phases.

\section{Acknowledgements}

The research is funded by the Ministry of Education and Science of the Russian Federation as part of the "Science" Program (project No. FSWW-2020-0014). The results of the phase composition of ferrite samples were obtained within the RFBR grant (project No. 20-07-00662).

\section{REFERENCES}

1 Letyuk L.M., Andreev V.G., Gonchar A.V., Strygin A.A. Magnetic-field effect on the rheological properties of strontium ferrite suspensions. Inorganic Materials. 2006, Vol.42, pp. 423 - 426.

2 Zhuravlev G.I., Golubkov L.A., Strakhova T.A. Basic types of microstructure of ferrites and means of obtaining them. Powder Metallurgy and Metal Ceramics. 1990, Vol.29, pp. $478-480$.

3 Jia L., Zhao Y., Xie F., Li Q., Li Y., Liu C., Zhang H. Composition, microstructures and ferrimagnetic properties of Bi-modified LiZnTiMn ferrites for LTCC application. AIP Advances. 2016, Vol.6, 056214.

4 Letyuk L.M. Recrystallization of ferrites and its effect on the processes of microstructure formation in ferrospinels. Powder Metallurgy and Metal Ceramics. 1980, Vol.19, No 5, pp. $359-364$.

5 Zinovik M.A., Zinovik E.V. Ferrites with rectangular and square hysteresis loops. Powder Metallurgy and Metal Ceramics. 2005, Vol.44, pp. $66-74$.

6 Andreev V.G., Letyuk, L.M., Maiorov V.R., Podgornaya S.V., Strygin, A.A. Binders in the manufacture of magnetic ceramics (ferrites). Steel in Translation. 2007, Vol.37, pp. $589-592$.

7 Sudakar C., Naik R., Lawes G., Mantese J.V., Micheli A.L., Srinivasan G., Alpay S.P. Internal magnetostatic potentials of magnetization-graded ferromagnetic materials. Applied Physics Letters. 2007, Vol.90, 062502. 
8 Teo M.L.S., Kong L.B., Li Z.W., Lin G.Q., Gan Y.B. Development of magneto-dielectric materials based on Li-ferrite ceramics I. Densification behavior and microstructure development. Journal of Alloys and Compounds. 2008, Vol.459, pp. 557-566.

9 Minin V.M. Effect of sintering conditions on the microstructure and electromagnetic properties of Li-Mg-Mn ferrite memory elements. Powder Metallurgy and Metal Ceramics. 1982, Vol.21, pp. 698 - 701.

10 LysenkoE.N.,SurzhikovA.P.,VlasovV.A.,NikolaevE.V.,MalyshevA.V.,Bryazgin

A.A.,Korobeynikov M.V., Mikhailenko M.A. Synthesis of substituted lithium ferrites under the pulsed and continuous electron beam heating. Nuclear Instruments and Methods in Physics Research, Section B: Beam Interactions with Materials and Atoms. 2017, V. 392, pp. 1-7.

11 Sharma P., Uniyal P. Investigating thermal and kinetic parameters of lithium titanate formation by solid-state method. Journal of Thermal Analysis and Calorimetry. 2017, Vol.128, pp. $875-882$.

12 Rakshit S.K., Parida S.C., Naik Y.P., Venugopal V. Thermodynamic studies on lithium ferrites. Journal of Solid State Chemistry. 2011, Vol.184, pp. 1186 - 1194.

13 Surzhikov A.P., Malyshev A.V., Lysenko E.N., Vlasov V.A., Sokolovskiy A.N. Structural, electromagnetic, and dielectric properties of lithium-zinc ferrite ceramics sintered by pulsed electron beam heating. Ceramics International. 2017, Vol. 43, No. 13, pp.9778-9782. DOI: .1016/j.ceramint. 2017.04. 155

14 El-Shobaky G.A., Ibrahim A.A. Solid-solid interactions between ferric oxide and lithium carbonate and the thermal stability of the lithium ferrites produced. Thermochim. Acta. 1987, Vol.118, pp. $151-158$.

15 Salimov R.A., Cherepkov V.G., Golubenko J.I., Krainov G.S., Korabelnikov Yu.A., Kuznetsov S.A., Kuksanov N.K., Malinin A.B., Nemytov P.I. D.C. high power electron accelerators of ELV-series: status, development, applications. Radiation Physics and Chemistry Journal. 2000, Vol.57, pp. 661 - 665.

16 Cleland M.R., Parks L.A. Medium and high-energy electron beam radiation processing equipment for commercial applications. Nuclear Instruments and Methods Journal. 2003, Vol.208, pp. 74 - 89.

17 Mehnert R. Review of industrial applications of electron accelerators. Nuclear Instruments and Methods Journal. 1996, Vol.113, pp. $81-87$.

18 Neronov V.A., Voronin A.P., Tatarintseva M.I., Melekhova T.E., Auslender V.L. Sintering under a high-power electron beam. Journal of the Less Common Metals. 1986, Vol.117, pp. 391 - 394.

19 Surzhikov A.P., Frangulyan T.S., Ghyngazov S.A. A thermoanalysis of phase transformations and linear shrinkage kinetics of ceramics made from ultrafine plasmochemical $\mathrm{ZrO} 2(\mathrm{Y})-\mathrm{Al}_{2} \mathrm{O}_{3}$ powders. Journal of Thermal Analysis and Calorimetry. 2014, Vol. 115, No. 2, pp. 1439-1445 DOI: 10.1007/s10973-013$3455-\mathrm{y}$

20 Surzhikov A.P., Galtseva O.V., Vasendina E.A., Vlasov V.A., Nikolaev E.V. Processing line for industrial radiation-thermal synthesis of doped lithium ferrite powders. Proceeding of the IOP Conference Series: Materials Science and Engineering. 2016, Vol.110, No.1, 012002 DOI: 10.1088/1757899X/110/1/012002.

21 Surzhikov A.P., Frangulyan T.S., Ghyngazov S.A., Lisenko E.N., Galtseva O.V. Physics of magnetic phenomena: Investigation of electroconductivity of lithium pentaferrite. Russian Physics Journal. 2006, Vol.49, No.5, pp. 506 - 510. 1717 DOI: 10.1007/s11182-006-0133-6

22 Lysenko, E.N., Surzhikov, A.P., Zhuravkov, S.P., Vlasov V.A., Pustovalov, A.V., Yavorovsky. The oxidation kinetics study of ultrafine iron powders by thermogravimetric analysis. Journal of Thermal Analysis and Calorimetry. 2014, Vol. 115, iss. 2, p. 1447-1452 DOI: 10.1007/s10973-013-3456-x

23 Surzhikov, A.P., Frangylyan, T.S., Ghyngazov, S.A. A dilatometric study of the effect of pressing on the kinetics of compression of ultrafine zirconium doxide powders under thermal annealing. Russian Physics Journal. 2012. Vol.55, No.4, pp. 345 - 352 DOI: 10.1007/s11182-012-9818-1

24 Burlakova R.F., Edel'man I.S., Zabluda V.V. Magnetic linear and circular dichroism of lithium ferrite. SOVIET PHYSICS SOLID STATE. 1978, Vol.20, pp. $1672-1673$.

25 Kong L.B., Teo M.L.S., Li Z.W., Lin G.Q., Gan Y.B. Development of magneto-dielectric materials based on Li-ferrite ceramics III. Complex relative permeability and magneto-dielectric properties. Journal of Alloys and Compounds. 2008, Vol.459, pp. 576-582.

26 Xu F., Zhang D., Wang G., Zhang H., Yang Y., Liao Y., Jin L., Rao Y., Li J., Xie F., Gan G. Influence of LZN nanoparticles on microstructure and magnetic properties of Bi-substituted LiZnTi lowsintering temperature ferrites. Ceramics International. 2019, Vol.45, pp. 1946-1949.

27 Cao X., Sun K., Sun C., Leng L. The study on microstructure and microwave-absorbing properties of lithium zinc ferrites doped with magnesium and copper. Journal of Magnetism and Magnetic Materials. 2009, Vol.321, pp. 2896-2901. 
28 Verma V., Pandey V., Singh S., Aloysius R.P., Annapoorni S., Kotanala R.K. Comparative study of structural and magnetic properties of nano-crystalline $\mathrm{Li}_{0.5} \mathrm{Fe}_{2.5} \mathrm{O}_{4}$ prepared by various methods. Physica $B$. 2009, Vol. 404, pp. 2309-2314.

29 Kumar P., Juneja J.K., Singh S., Raina K.K., Prakash C. Improved dielectric and magnetic properties in modified lithium-ferrites. Ceramics International. 2015, Vol. 41. pp. 3293-3297.

30 Widatallah H.M., Johnson C., Berry F.J. The influence of ball milling and subcequent calcination on the formation of $\mathrm{LiFeO}_{2}$. Journal of Materials Science. 2002, Vol.37, pp. 4621-4625.

31 Berbenni V., Marini A., Matteazzi P., Ricceri R., Welham N.J. Solid-state formation of lithium ferrites from mechanically activated $\mathrm{Li}_{2} \mathrm{CO}_{3}-\mathrm{Fe}_{2} \mathrm{O}_{3}$ mixtures. Journal of the European Ceramic Society. 2003, Vol.23, pp. $527-536$.

32 Parvin R., Momin A.A., Akther Hossain A.K.M. J. Improvement of microstructure, initial permeability, magnetization and dielectric properties of nanocrystalline $\mathrm{Li}_{\mathrm{x}} \mathrm{Cu}_{0.1} \mathrm{Co}_{0.1} \mathrm{Zn}_{0.8-2 \mathrm{x}} \mathrm{Fe}_{2+\mathrm{x}} \mathrm{O}_{4}$. Journal of Magnetism and Magnetic Materials. 2016, Vol. 401, pp. 760 - 769.

33 Widatallah H.M., Ren X.L., Al-Omari I.A. The influence of $\mathrm{TiO}_{2}$ polymorph, mechanical milling and subsequent sintering on the formation of Ti-substituted spinel-related $\mathrm{Li}_{0.5} \mathrm{Fe}_{2.5} \mathrm{O}_{4}$. Journal of Materials Science. 2006, Vol.41, pp. $6333-6338$.

34 Yesbayev A.N., Yessenbayeva G.A., Ramazanov M.I. Investigation of the model for the essentially loaded heat equation. Eurasian Physical Technical Journal. 2019, Vol.16, No.1, pp. 113 - 120.

35 Zhumabekov A.Z., Seliverstova E.V., Ibrayev N.K. Investigation of photocatalytic activity of $\mathrm{TiO}_{2}$-GO nanocomposite. Eurasian Physical Technical Journal. 2019, Vol.16, No.1, pp. 42 - 46.

36 Liao Y., Wang Y., Chen Zh., Wang X., Lib J., Guo R., Liu Ch., Gan G., Wang G., Li Y., Zhang H. Microstructure and enhanced magnetic properties of low-temperature sintered LiZnTiMn ferrite ceramics with $\mathrm{Bi}_{2} \mathrm{O}_{3}-\mathrm{Al}_{2} \mathrm{O}_{3}$ additive. Ceramics International. 2020. Vol.46, No.1, pp. $487-492$.

37 Ahniyaz A., Fujiwara T., Song S-W., Yoshimura M. Low temperature preparation of $\beta-\mathrm{LiFe}_{5} \mathrm{O}_{8}$ fine particles by hydrothermal ball milling. Solid State Ionics. 2002, Vol.151, No.1-4, pp. $419-423$.

38 An S.Y., Shim I-B., Kim C.S. Synthesis and magnetic properties of $\mathrm{LiFe}_{5} \mathrm{O}_{8}$ powders by a sol-gel process. Journal of Magnetism and Magnetic Materials. 2005, Vol.290, pp. 1551 - 1554.

39 Petrova A.B., Astafyev A.L., Ershov A.V. The study of initial permeability temperature dependences for LiTiZn ferrite ceramics. IOP Conference Series: Materials Science and Engineering. 2018, Vol. 81(289), pp.133575. DOI: 10.1088/1757-899X/289/1/012042.

40 Kavanlooee M., Hashemi B., Maleki-Ghaleh H., Kavanlooee J. Effect of annealing on phase evolution, microstructure, and magnetic properties of nanocrystalline ball-milled LiZnTi ferrite. Journal of Electronic Materials. 2012, Vol. 41, pp. 3082-3086.

41 Barba A., Clausell C., Feliu C., Monzo M. Sintering of $\left(\mathrm{Cu}_{0.25} \mathrm{Ni}_{0.25} \mathrm{Zn}_{0.50}\right) \mathrm{Fe}_{2} \mathrm{O}_{4}$ ferrite. Journal of the American Ceramic Societ. 2004, Vol.87, No.4, pp. 571 - 577. 